\title{
Differences between mouse strains in their consumption of phenylthiourea (PTC)
}

Ian E. Lush

Department of Genetics and Biometry, University College London, Wolfson House, 4 Stephenson Way, London NW1 2HE.

Mice from 25 laboratory strains were given the choice of drinking a dilute (100 mg/litre) solution of phenylthiourea (PTC) or a control solution containing no PTC. The consumption of PTC by each strain was measured daily over a period of 10 days. There was considerable variation between strains in their consumption of PTC. The mean PTC consumption of the 13 albino strains was less than the mean of the 12 pigmented strains. Most strains showed a decrease in PTC consumption during the $\mathbf{1 0}$ days of the experiment and the albino strains showed, on average, a greater decrease than did the pigmented strains. Tests with congenic strains proved that the albino allele itself is not the cause of the reduced PTC consumption. The possibility of a gene which is linked to the albino locus and which has an effect on PTC consumption is discussed.

\section{INTRODUCTION}

Hoshishima et al. (1962) tested three black and three albino strains of mice for their ability to taste the bitter substance phenylthiourea (PTC) and concluded that the albino strains had lower taste thresholds for PTC than did the black strains. Klein and DeFries (1970) later claimed that one major gene determines the sensitivity of mice to the taste of PTC. Neither of these two conclusions has been independently verified, although the one-gene hypothesis has been uncritically accepted and is now quoted as fact in at least one textbook of genetics (Emery, 1983). The results presented here confirm that albino strains show, on average, a greater sensitivity to PTC, as measured by their avoidance of drinking it. However the genetical determination of PTC avoidance was found to be more complicated than was suggested by Klein and DeFries. These results have been published in summary elsewhere (Lush, 1982).

\section{MATERIALS AND METHODS}

Adult mice of both sexes, 2 to 6 months old, were used. The full designations of the 25 strains used are as follows: A/Gr, AKR/J, Au/SsJ, A2G/Lac, $\mathrm{BALB} / \mathrm{cBy}, \mathrm{CBA} / \mathrm{Ca}, \mathrm{CE} / \mathrm{J}, \mathrm{C} 3 \mathrm{H} / \mathrm{He}$,
C57BL/6By, C57BL/10ScSn, C57L/Lac, DBA/1Lac, DBA/2Pas, NMRI/Lac, NZB, Schneider, SEA/GnJ, Simpson, SM/J, ST/bJ, STS/A, SWR/J, TO, 129/RrJ, 129/Sv. These strains vary in pigmentation from black to pinkeyed white (albino). The CXB recombinant inbred (RI) strains were developed by Dr Donald Bailey (Jackson Laboratory, Bar Harbour) from the founder strains $\mathrm{C} 57 \mathrm{BL} / 6 \mathrm{By}$ and $\mathrm{BALB} / \mathrm{cBy}$. The albino congenic strains $\mathrm{C} 57 \mathrm{BL} / 10-c$ and $\mathrm{C} 3 \mathrm{H}-c$ were developed by Dr. Michael Festing (MRC Laboratory Animals Centre, Carshalton) and each had undergone seven cycles of backcrossing to $\mathrm{C} 57 \mathrm{BL} / 10$ and $\mathrm{C} 3 \mathrm{H}$ respectively.

The tastant solution was $100 \mathrm{mg}$ PTC (BDH Chemicals Ltd.) dissolved in $10 \mathrm{ml}$ ethanol and then diluted to 1 litre with tap water or distilled water. The control solution was $10 \mathrm{ml}$ ethanol diluted to 1 litre with water. The experimental procedure has been fully described elsewhere (Lush 1984). The basic schedule takes 4 days. The caged mice are presented with two drinking spouts connected to burettes. One burette contains the tastant and the other burette contains the control solution. The consumption of tastant is measured after one day and expressed as a percentage of the total fluid intake for that day. For the second day the positions of the spout-burette units are reversed and the percentage consumption of tastant is again 
calculated. For the third day the spout-burette units remain in position but their contents are reversed. For the fourth day the spout-burette units are changed back to their original positions, although with their contents still reversed. These changes of position and content are to cancel the effects of any preferences by the mice for drinking from one position or from one spout. In the present investigation the whole 4-day schedule was repeated once, and then the first 2 days of the schedule were repeated again. This gave a complete sequence of ten daily measurements of the percentage consumption of tastant. Between two and seven cages from each strain were tested. Each cage contained between one and four mice.

\section{RESULTS}

The result of a survey of all 25 strains is shown in fig. 1. In order to smooth out the daily variation the data for each strain are presented as a series of 4-day running means. In group $A$ are the 12 strains with the wild-type allele of the albino gene; in group $B$ are the 12 albino strains and strain $C E$, which has the "extreme dilution" $\left(c^{\mathrm{e}}\right)$ allele of the albino gene. The results show a clear difference between these two groups. The data are summarised in table 1 where it can be seen that the means of both groups fell during the experiment, but the rate of fall of group B was about twice that in group $A$, with the result that the difference between the two groups increased as the experiment progressed.

Table 1 The mean percentage consumption $( \pm$ SEM) of PTC for each 4-day period by the two groups of strains. Data taken from fig. 1

\begin{tabular}{lrrrrrrr}
\hline \multicolumn{7}{c}{ 4-day periods } \\
& $1-4$ & $2-5$ & $3-6$ & $4-7$ & $5-8$ & $6-9$ & $7-10$ \\
\hline Pigmented & 49.6 & 47.7 & 46.8 & 46.8 & 45.0 & 44.8 & 43.6 \\
strains & \pm 1.7 & \pm 1.2 & \pm 1.3 & \pm 1.4 & \pm 1.4 & \pm 1.4 & \pm 1.7 \\
Albino & 37.0 & 36.5 & 34.2 & 31.5 & 27.4 & 28.2 & 26.5 \\
strains & \pm 2.5 & \pm 2.5 & \pm 2.4 & \pm 2.6 & \pm 2.7 & \pm 2.9 & \pm 2.9 \\
$\quad$ & & & & & & & \\
\hline
\end{tabular}
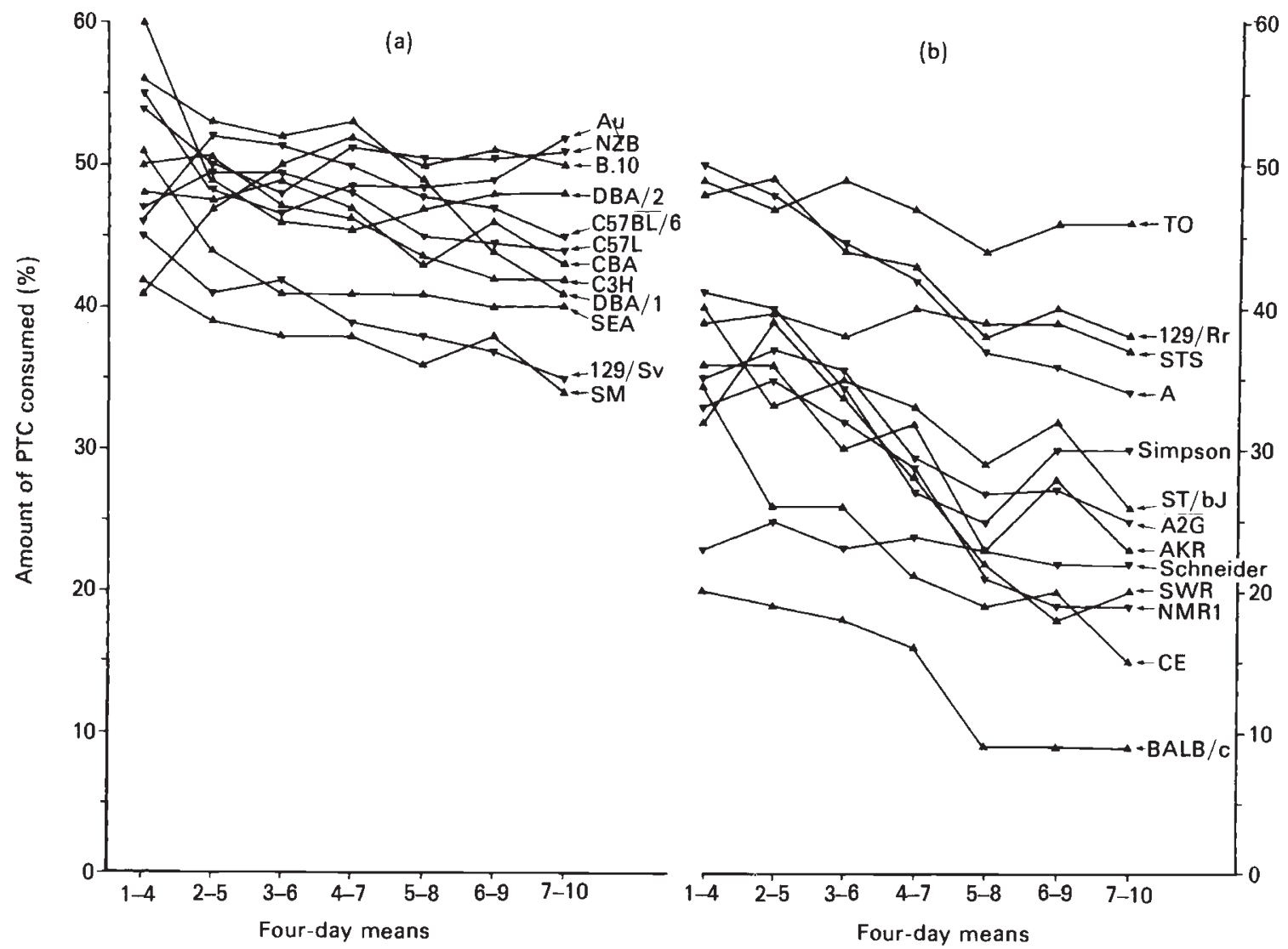

Figure 1 Consumption of PTC by 25 strains. (a): pigmented strains. (b): albino strains and CE. 
$\mathrm{BALB} / \mathrm{c}$ (albino) was the strain which showed the lowest consumption of PTC, and its consumption dropped further in the course of the experiment. On the other hand C57BL/6 (pigmented) showed no significant avoidance of PTC and consumed as much during days $7-10$ as during days 1-4. If the difference between these two strains is largely due to a single gene it should be possible to demonstrate this by the use of the CXB RI strains. The seven RI strains were therefore tested and the results are shown in fig. 2(a). The only two albino strains, $G$ and $I$, closely resembled BALB/c. However most of the pigmented strains were not classifiable as $\mathrm{C} 57 \mathrm{BL} / 6$-like but were intermediate and rather variable in their behaviour.

The availability of the two congenic strains $\mathrm{C} 57 \mathrm{BL} / 10-c$ and $\mathrm{C} 3 \mathrm{H}-c$ made it possible to subject the association between albinism and the avoidance of PTC to a more critical test. Five C57BL/10$c$ and two $\mathrm{C} 3 \mathrm{H}-c$ mice were individually tested with PTC. All of them gave results which were

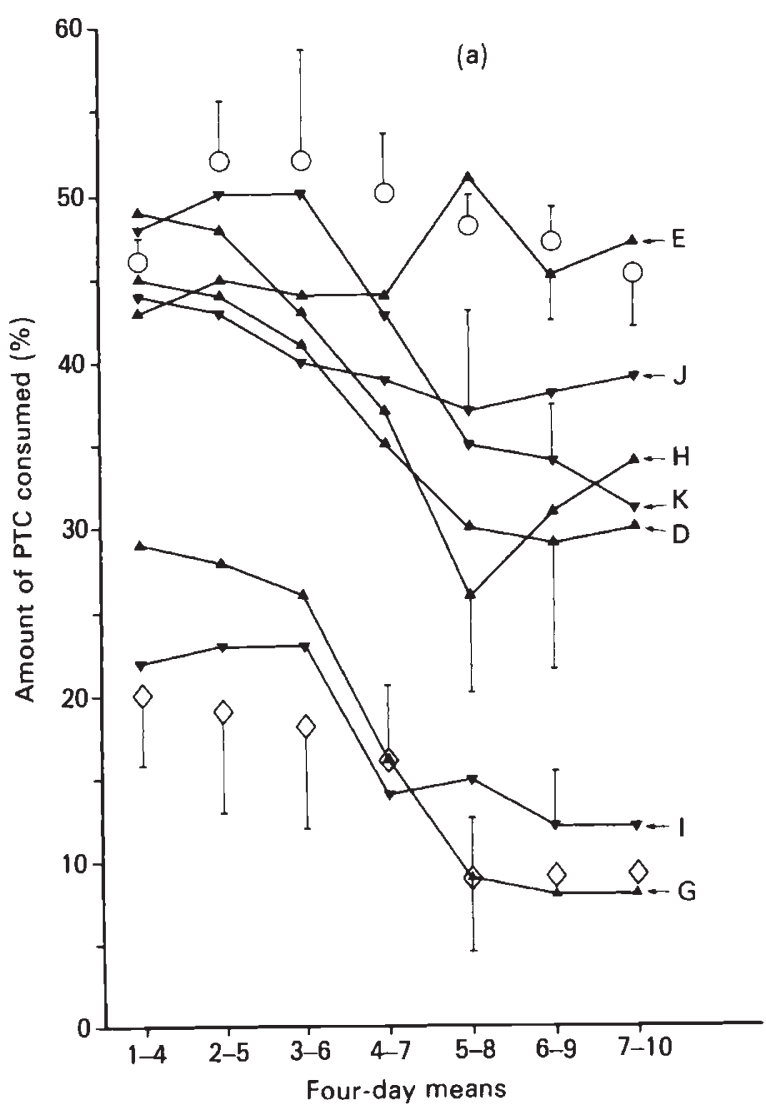

typical of pigmented strains, thus showing no effect of the presence of the homozygous albino allele. The means of each of the two congenic strains are shown in Fig. 2(b). This result appeared to rule out any direct effect of the albino allele on PTC consumption, but it left open the possibility that a gene linked to the albino locus has such an effect. In an attempt to detect this hypothetical linked gene some $F_{1}$ mice were produced from a $\mathrm{C} 57 \mathrm{BL} / 6 \times \mathrm{BALB} / \mathrm{c}$ cross, and also from the reciprocal cross (the female parent is written first). One cage of mice from each kind of $F_{1}$ was tested and both consistently avoided the PTC. The mean of the two $F_{1}$ experiments is shown in Fig. 2(b). In the hope of detecting segregation, a $\mathrm{C} 57 \mathrm{BL} / 6 \times$ $(\mathrm{C} 57 \mathrm{BL} / 6 \times \mathrm{BALB} / \mathrm{c}) \mathrm{F}_{1}$ backcross was made and 16 of the progeny of this cross were tested. No segregation was detectable because none of the progeny resembled the $F_{1}$ parent, indeed only one progeny mouse showed any significant avoidance of PTC. The mean of the 16 backcross progeny is shown in Fig. 2(b).

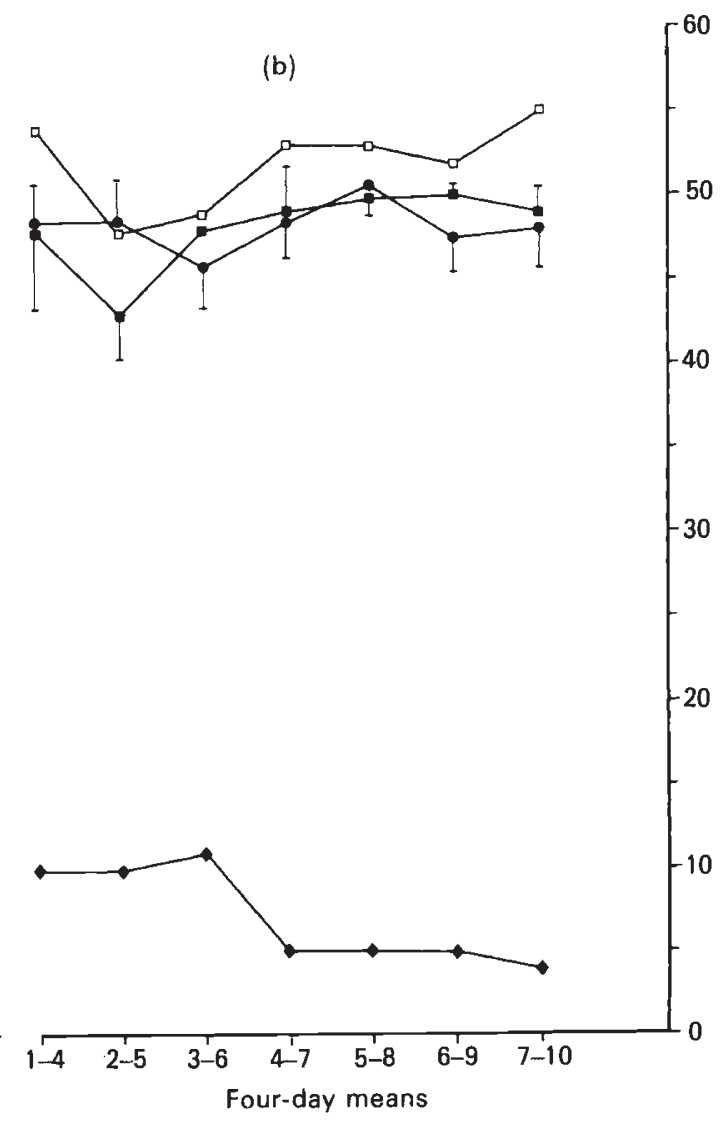

Figure 2 Consumption of PTC by different kinds of mice. (a): $O=C 57 B L / 6 B y, \diamond=B A L B / c B y, \Delta$ and $\nabla=C X B$ RI lines. (b): $\square=\mathrm{C} 3 \mathrm{H}-c, \square=\mathrm{C} 57 \mathrm{BL} / 10-c, \diamond=(\mathrm{C} 57 \mathrm{BL} / 6 \times \mathrm{BALB} / \mathrm{c}) \mathrm{F}_{1}, \mathrm{O}=$ progeny of the backcross $\mathrm{C} 57 \mathrm{BL} / 6 \times \mathrm{F}_{1}$. Vertical bars are SEMs. 


\section{DISCUSSION}

The results show that there is variation between strains of mice in their consumption of the PTC solution. Some strains, for example Au, NZB and C57BL/ 10 consume PTC freely. Other strains, such as Schneider and BALB/c, strongly avoid drinking PTC. Some other points emerge clearly from the data in fig. 1 and table 1 . The first point is that most strains show a decline in the consumption of PTC during the 10 days of the experiment. The second point is that, on average, albino strains (including $\mathrm{CE}$ ) consume less PTC than do pigmented strains. And because the consumption declines faster in the albino strains than in the pigmented strains there is very little overlap between the two groups at the end of the 10 days of the experiment.

A genetical explanation of the above facts proved to be elusive. The association between albinism and decreased consumption of PTC cannot be due to the albino allele itself. This conclusion follows inescapably from the results with the congenic strains C57BL/10-c and C $3 \mathrm{H}-c$ both of which, although albino, gave results typical of pigmented strains. Indeed the albino strain TO also gave a result similar to the pigmented strains. An alternative explanation is that the decreased consumption is caused by a gene which is linked to the albino locus. But this would imply that one allele of the linked gene is restricted almost entirely to albino strains of mice. At first sight is seems extremely unlikely that such an extensive disequilibrium could exist among laboratory strains. It could have arisen if all the albino strains had obtained their albino allele from the same original source, and if this albino allele had brought with it, as a hitch-hiker, the closely linked allele which causes decreased PTC consumption. The standard genealogy of inbred strains (Altman and Katz, 1979) does not support this idea, although it must be admitted that there is considerable uncertainty about the precise origin of many of the strains. Strain CE is interesting in this respect because of $c^{\mathfrak{e}}$ allele is known to have originated in a wild mouse trapped in Illinois, USA, in 1920. However it could have acquired the hypothetical linked allele (which confers decreased PTC consumption) by recombination during the tests for allelism which must have been carried out with one of the existing albino strains.

The disequilibrium could equally have arisen if all the pigmented strains had obtained their wild-type allele at the $C$ (albino) locus from the same original source and this wild-type allele had brought with it a closely-linked allele which causes increased PTC consumption. Mouse geneticists have had to digest some recent experimental results with very surprising implications for the origins of standard laboratory strains (Ferris et al., 1982: Bishop et al., 1985). Perhaps one should await further developments in this field before coming to any firm conclusions.

The results obtained with the CXB RI strains (fig. 2(a)) are compatible with the hypothesis of a linked gene if it is assumed that there was no recombination between the albino locus and the linked gene during the derivation of the RI strains. Thus RI strains $G$ and I have inherited both their albino allele and their increased aversion to PTC from their $\mathrm{BALB} / \mathrm{c}$ progenitor. The results obtained with the two congenic strains are also compatible with this hypothesis if one assumes that in both strains the linked allele was separated from the albino allele during the repeated backcrossing involved in putting the albino allele on the $\mathrm{C} 57 \mathrm{BL} / 10$ or $\mathrm{C} 3 \mathrm{H}$ background.

Leaving aside the association between PTC avoidance and albinism, the data as a whole do not support the conclusion of Klein and DeFries (1970) that "PTC taste sensitivity is determined by a single locus in mice, similar to that in man". There is wide and continuous variation between the 25 strains shown in fig. 1 and this probably has a multigenic basis. Klein and DeFries (1970) support their claim with data from crosses using C57BL/6 and BALB/c, yet some of the CXB RI strains shown in fig. 2(a) seem to be intermediate in character between C57BL/6 and BALB/c and this argues for more than one gene being involved in the difference between these two strains. Moreover, the progeny of the $\mathrm{C} 57 \mathrm{BL} / 6 \times$ $(\mathrm{C} 57 \mathrm{BL} / 6 \times \mathrm{BALBC} / \mathrm{c}) \mathrm{F}_{1}$ backcross shown in fig. 2(b) do not show segregation of a single gene. Indeed the backcross results do not admit of any simple explanation.

Strain and individual differences in PTC consumption could depend on differences in tasting ability, in dislike of the taste, in sensitivity to any ill-effects of PTC, or in learning.

\section{REFERENCES}

ALTMAN, P. L. AND KATZ, D. D. (eds.) 1979. Inbred and genetically defined strains of laboratory animals. Part 1. Mouse and rat. Federation of American Societies for Experimental Biology, Bethesda, U.S.A.

BISHOP, C. E., BOURSOT, B., BONHOMME, F. AND HATAT, D. 1985. Most classical Mus musculus domesticus laboratory strains carry a Mus musculus musculus $\mathrm{Y}$ chromosome. Nature, 315, 70-72. 
EMERY, A. E. H. 1983. Elements of Medical Genetics 6th Edn. Churchill-Livingston, Edinburgh, p 191.

FERRIS, S. D., SAGE, R. D. AND WILSON, A. C. 1982. Evidence from mtDNA sequences that common laboratory strains of inbred mice are descended from a single female. Nature, $295,163-165$.

HOSHISHIMA, K., YoKoYAMA, S. AND SETO, K. 1962. Taste sensitivity in various strains of mice. Amer. J. Physiol., 202, 1200-1204.
KLEIN, T. W. AND DEFRIES, J. C. 1970. Similar polymorphism of taste sensitivity to PTC in mice and men. Nature, 225, 555-557.

LUSH, I. E. 1982. Pigmentation and PTC tasting in the laboratory mouse (abstract). Genetical Research, 40, 100-101.

LUSH, I.E. 1984. The genetics of tasting in mice. III. Quinine. Genetical Research, 44, 151-160. 